Journal of

Strategic Management

(JSM)



Organizational Change and the Imperatives of Managing Employee Resistance: A Conceptual Review

Dr. Miebaka Dagogo Tamunomiebi

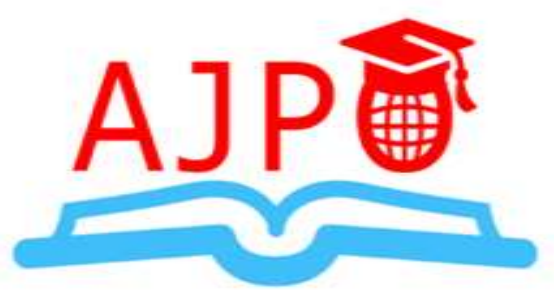

Akpan Enefiok Peter 


\title{
Organizational Change and the Imperatives of Managing Employee Resistance: A Conceptual Review
}

\author{
${ }^{1}$ Dr. Miebaka Dagogo Tamunomiebi and ${ }^{2}$ Akpan, Enefiok Peter
}

${ }^{1}$ Department of Management, Faculty of Management Sciences, Rivers, State University, Nkpolu-Oroworukwo, PMB 5080, Port Harcourt, Nigeria.

\section{tamunomiebi2002@yahoo.com}

\author{
${ }^{2}$ Doctoral Candidate Department of Management, Faculty of Management Sciences, \\ Rivers State Universityf, Nkpolu-Oroworukwo, PMB 5080, Port Harcourt, Nigeria. \\ Enefiok.Akpan1@gmail.com
}

\begin{abstract}
Purpose: The purpose of this paper was to critically examine the factors that engender employee resistance to change and the various organizational strategies aimed at managing employee resistance to change.

Methodology: The paper is a conceptual review of literature and thus adopted a desk research methodology to review extant literature on the subject matter.

Findings: based on reviewed literature, managing and leading employees in a changing environment is critical to overall business success. A significant problem for many business leaders is that they fear employee resistance and do not use resistance as an opportunity to engage and learn.

Unique Contribution: This study provides meaningful insight to the strategies needed to manage change which is seen as a permanent business function to improve efficiency and keep organizations adaptable to the competitive marketplace.

Recommendation: Organizations must act in a proactive manner in managing incivility so that it does degenerate to serious and corrosive consequences that eat away the workplace culture by promoting well-being in the workplace and preventing certain unsafe dynamics from establishing themselves.
\end{abstract}

Keywords: Organizational Change, Resistance to Change, Communication, Collaboration, Negotiating and Motivation 


\section{Introduction}

Change is very risky as evidence suggests that only 30 percent of change is successful. With such hugely unfavourable odds, it is imperative that companies get it right from the beginning to avoid their strategies to fail (Prokesch, 2009). The business environment has also become more complex and turbulent which has resulted to organizations having to adapt to these changes (Alexander, 2007). Organizations today are rapidly encountering change in the external environment but are not able to implement new strategies because there would be resistance to change within the organization (Burns, 2004).

The change management process is not an easy process (Lawrence, 2013). There are two sides in the change management process, some of the employee's understand the need of change and the other employee's do not understand the need of change and so they resist to this change (Burke \& Ghada, 2014). Many people in organization do not like change, and so they resist to this change, as addressed earlier, change is important to any organization to stay competitive in the turbulent environment (Darling \& Taylor, 2005).

In this modern era, everything will change because change is everywhere, including in an organization. Changes are made so that the organization remains dynamic, while at the same time to improve organizational progress and employee's performance, adapt to the environment, and change behaviour patterns in the workplace (Leana \& Barry, 2000). This confirms that organizations that make changes are organizations that want to survive. Change is defined as a process that changes the direction of history or development and can influence the system or functionality of an organization (Abraham, 2000). However, not all planned changes can be successful and can be accepted by all employees. In fact, the rate of failure of organizational change turns out to be up to $70 \%$ (Balogun \& Hailey, 2004). It explains that success in change depends on how employees respond to these changes because, in essence, each employee must have a different perspective with other employees in responding to a change (Lines, 2004). Not all employees react positively to change; some even react negatively, and one of the employees' negative attitudes to change is called resistance to change (Piderit, 2000).

The purpose of this paper was to examine the factors that engender employee resistance to change and the various organizational strategies aimed at managing employee resistance to change.

\section{Theoretical Foundation}

\section{Three-Step Change Theory}

Kurt Lewin (1951) developed a three-step change model by introducing the concept of force field analysis, which examines the driving and resisting forces in any change situation. The positive, driving forces which facilitate change push employees in the desired direction to accept the change plans. On the other hand, negative, constraining forces may hinder change plans as these factors might push employees in the opposite direction resulting in the failure of the change plans. Therefore, these forces must be analyzed and Lewin's three-step model can help shift the balance in the direction of the planned change according to the strategic plan of the organisation (Okenda, Thuo, \& Kithinji, 2017). 
The first step of Lewin's model of change begins with unfreezing the existing situation or status quo. Unfreezing is necessary to overcome the strains of individual resistance and group conformity. Unfreezing can be achieved by the use of three methods. First, increase the driving forces that direct behaviour away from the existing situation or status quo. Second, decrease the restraining forces that negatively affect the movement from the existing equilibrium. Third, find a combination of the two methods listed above. Some activities that can assist in the unfreezing step include: motivate participants by preparing them for change, build trust and recognition for the need to change, and actively participate in recognizing problems and brainstorming solutions within a group.

In the second step, Lewin posits that the process of changing behaviour is a movement (Hobman, \& Walker, 2015). It is thus necessary to cause a disturbance and move the target system to a new level of equilibrium. In this step three actions are also necessary to assist in instituting the movement: persuading employees to agree that the status quo is not beneficial to them and encouraging them to view the problem from a fresh perspective, work together on a quest for new, relevant information, and connect the views of the group to well-respected, powerful leaders that also support the change.

In the final and the third step of Lewin's three-step change model is refreezing. In this step, Lewin recognizes that once change has been implemented for it to be sustained or stick over time, refreezing is important. It is highly likely that the change will be short lived and the employees will revert to their old equilibrium (behaviours) if this step is not taken. It is the actual integration of the new values into the community values and traditions. The crucial action to be taken for the change to be sustained, Lwein states that the third step requires institutionalizing the change through formal and informal mechanisms including policies and procedures (Franck, Roes, De Schepper \& Timmermans, 2018). Thus, sustained change will occur when the combined strength of forward force is greater than the combined strength of the opposing set of forces (Okenda et al., 2017).

\section{Organizational Change}

Organizational change management has been defined by Moran and Brightman (2011) as the process of continually renewing an organization's direction, structure and capabilities to serve the ever changing needs of external and internal customers. Raineri (2011) sees change management practices as a variety of organizational interventions that when executed properly and in consistency with internal and external organizational events, facilitate the enactment of organizational change processes. Korir, Mukotive, Loice and Kimeli (2012) defined change management as the effective management of a business change such that executive leaders, managers and frontline employers work in concert to successfully implement the needed process, technology or organizational changes.

Change in organizations does not happen in a vacuum. Johnson and Scholes (2002), identify political, economic, social, technological and ecological factors as comprising the external environment that present the organization with opportunities, threats and constraints. They pointed out that these factors produce powerful forces in the environment that pressurizes both the public and private organizations to alter permanently existing strategy, structure, policies, technology and practices. This in turn implies that the aim of organizational change is an adaptation of the environment to improve its performance. 


\section{Types of Organizational Change}

Many organizations have undergone substantial change and the pace of change is increasing (Paton \& McCalman, 2011). Organizational change can occur on any level of the organization, it can occur on the operational level which requires simple changes to day-to-day tasks, that engages in improving performance (Lawrence, 2013). On the other hand change can also be at top level or the strategic level that impacts on the mission and vision of the company (Kotter \& Cohen, 2002). As per Price and Chahal (2007) if change managers are to develop effective implementation of change strategies, they need to understand the different types of change; crisis change which is a reactive approach driven by external factors and fear of failure and the chosen change which is more a proactive approach driven by a workforce committed to the success of an organization.

However, previous scholars such as Balogun and Hailey (2008) described three main types of organization change; Developmental change: the doing more of, or better than, what currently exists; Transitional change: implementation of a new desired state requiring dismantling existing ways; Transformational change: implementing an evolutionary new state, requiring major and ongoing shifts in organizational strategy and vision. Paton and McCalman (2011) model identifies four types of organizational change by cross-referencing anticipatory and reactive change with incremental and strategic change. Four resulting types of change are tuning, adaptation, reorientation, and recreation.

\section{Resistance to Change}

Resistance to change can be interpreted as an attitude or behaviour of an individual who can frustrate the purpose of change goals (Chawla \& Kelloway, 2004). Employee adverse reactions to changes will have enormous consequences; this is because they will inhibit the success of the planned changes (Fugate, Prussia \& Kinicki, 2012). The facts show that one of the factors that causes the failure of organizational change is employees who resistance to change (Regar et al., 1994). Generally, resistance is an individual reaction that arises from opposition to change (Folger \& Skarlicki, 1999). Meanwhile, Oreg (2006) in his research, states that resistance to change is an individual characteristic that shows a negative attitude to change, and there is a tendency to avoid and even fight against it. Employees who have resistance to change must have specific goals and objectives for management; therefore, resistance to change is an essential factor for consideration of organizational change programs. Forms of resistance carried out by employees, include: boycotting, reduced interest, blocking, opposing views, strikes, to negative perceptions and attitudes (Coetsee, 1999).

People's reactions to change will depend on the benefits that they think will result from it. If they believe they will profit from change, they will support it; if they feel they will lose status, prestige, earning power, or the job itself because of change, they will fight it. Evaluation of change will almost always lead to one of the four reactions: rejection, resistance, tolerance or acceptance (Julia and Veronica, 2008). Employee resistance can either be overt or covert. Overt resistance is observable; management can see it. Work slowdown, the setting of lower informal production norms, and outright sabotage are examples. Covert resistance is not readily observable because it is done under the guise of working as usual. 
According to De jager (2001), employees resist change because they have to learn something new. In many cases, there is no disagreement with the benefits of the new process, but rather a fear of the unknown future and about the ability to adapt to it. According to Greenberg and Baron (2002), a distinction exists between primary and secondary causes of resistance. Primary sources of resistance are perceived as being directly linked to the content of change. This is often the case when change has detrimental effects on the work conditions. In contrast, secondary causes of resistance are defined as barriers that directly or indirectly hinder the implementation of the change. Examples of secondary causes of employee resistance include; lack of time, resources, competencies, and absence of a clear plan to implement change.

\section{Impact of Resistance to Change}

The resistance of employees to change that occurs in an organization will bring a negative impact on the sustainability of the organization's growth, because resistance to change is a negative reaction of employees that inhibit change. The negative effects of resistance to change in an organization include reducing job satisfaction (Wanberg \& Banas, 2000; Burke et al., 2009), reducing perceived organizational effectiveness (Jones \& Ven, 2016), and minimizing creative performance (Hon et al., 2011). In addition, as a result of employee resistance to change turned out to be referred to as one of the main obstacles to organizational change initiatives (Lippert \& Davis, 2006), and cause negative impacts such as reducing employee motivation (Ude \& Diala, 2015), less than optimal results of failure change programs (Giangreco \& Peccei, 2005), reducing employees' adaptability to work and causing organizational setbacks and ultimately increasing turnover (Oreg, 2006). On the other hand, not all consequences of resistance to change have a negative impact, but there are also positive effects. Piderit (2000) has found that resistance to change is also able to provide a useful source of information for learning how to develop a more successful change process.

\section{Forces Leading to Employee Resistance to Change}

Resistance to change is a natural defence mechanism by employees as they wary when they are stepping into unfamiliar territory of change (Darling \& Taylor, 2005). It is commonly known that for some employees the best defence is a good offense which is the resisting force. Laws of physics state that it takes a certain amount of energy to overcome inertia, and that resistance (friction) is a force that will slow down a moving object (Wenhe, 2011). After studying the different causes of employees' resistance to change as discussed by different authors, Julia and Veroica (2008) were able to divide these causes in four different categories, based on the nature of resistance causes. These categories include;

Psychological:- Employees negative perception, frustration, anxiety, preference towards status quo, cognitive comfort, fear, past failure, Cynicism or mistrust in top management/owner (Val \& Fuentes 2003); Materialistic:- Loss of pay, comfort, status, and threat to job security (Dent \& Goldberg 1999); Employees' constant capabilities:- Employee's skills (existing), knowledge, \& expertise getting obsolete i.e. capabilities gap, embedded routines (Val \& Fuentes 2003). 
The most powerful barriers to change include (Lunenburg, 2010): insecurity, concerns about personal loss, group resistance, dependence, confidence in administration and awareness of weaknesses related to the proposed change. Approaches that explain the employee's resistant behaviour vary considerably depending on the viewpoints of the researchers. Resistance to change is an action undertaken by individuals or groups when they perceive change as a threat. Employees tend to have a high inclination to make changes when environmental factors pose no other choice than change, so in this situation the organization's employees are forced to change (Eseroghene \& Aguenza, 2016). Eseroghene and Aguenza (2016) point out that employees tend to show resistance to change even when business environment factors disappear. Reasons for employee resistance to change are different and vary depending on the individual's personality. An employee can well accept a change, while another looks angrily. Managers need to be aware that employees can withstand changes in different ways.

According to Zander (quoted in Mutihac, 2010), there are five main reasons for resisting change: - uncertainty about the nature of change, different interpretations regarding its change and impact, strong forces prevent individuals from change, top-down forces impose on individuals who are affected by change and personal interest in direction of change. Other factors that engender employee resistance to change are:

\section{Uncertainty}

Uncertainty during the change process is typically about the aim, process and expected outcomes of the change and suggestions for the individual employees (Huse, 2008). According to Kotter (2008) most people fear the unknown, particularly in the workplace, where staff grow accustomed to certain processes and procedures. Employees usually hang on to the fear, uncertainty, resentment and other emotions that big changes bring if it seems to them that management has no clue about how they feel (Wenhe, 2011). Fear is often one of the most common reasons for resisting change as the employee has fear of the unknown, of failure, loss or leaving a comfort zone. This fear is usually caused by uncertainty (McKnight, 2005). Bryant (2011) noted that uncertainty in employee's can be caused by; basic predisposition to change which is derived from birth experiences, early feeding and weaning, toilet training, sibling rivalries etc., personal sense of security which dependent on individual personality and current circumstances such as financial and marital status, prevailing cultural beliefs, relating to a particular country or community, class, trade or even work group and extent of trust and loyalty which results from past and present relationships with management, union and work groups.

\section{Mistrust in the Management}

Trust in management refers to the psychological contract established between individuals and organizations based on the messages an employee receives regarding organizational expectations and employee perceptions of desired managerial actions (Fred, 2012). Morrison (2015) suggests that trust is a vital tool in management to have implementation of new strategies in the organization. In organizations where there is a lot of trust in the management, there will be lower resistance to change. Mutual mistrust between the management and the employees if the organization will lead to the company going into a downward spiral as the firm's strategies will not be implemented as wanted, so trust is a must. Another common reason that Morrison (2015) brought to the table was that people resist organizational change because they assess the situation differently from their managers. 
Different assessments of the situation by employees can also create mistrust in the management, this is mainly because of poor leadership skill and communication which makes the employees not to trust the management (Schermerhorn, Hunt \& Osborn, 2005). Also the study by Davis (2012) found that many employees resisted change because of past experience with the management that lead to the mistrust in management.

\section{Employees Self Interest}

One another major reason employees resist organizational change is that they believe that they will lose something of value as a result. It could be power, position, title or they could be moved to the unknown state (Schermerhorn, Hunt \& Osborn, 2005). In such cases, people focus on their own best interests and not of those of the total organization, resistance and often results in "politics" or "political behaviour (Jansen, 2012). According to Morrison (2015) one of the major concerns of self-interest of the employees is the loss of control of the environment they are working in, this is another key reason why employees resist change as familiar routines help employees develop a sense of control over their environment they are working in. When employees are asked to change the way they work and operate, it may make employees feel powerless and confused. People are more likely to understand and implement changes when they feel they have some form of control (Burke \& Ghada, 2014).

\section{Strategies to Managing Resistance to Change}

Change is important to the organization today as organizations need to stay competitive in the industry they are working in. Manager can be able to manage change in various ways (Wenhe, 2011). John Kotter one of the Gurus of change talks about his 8-Step model to help in implementation of change, the 8-Step Model is a classic model which has formed the base on many change management models (Senior \& Fleming, 2004). Hansen, Randolph, Chen, Robinson, Marin and Lee (2015) argued that business leaders must also manage the people within its walls as many institutionalized opponents can negatively influence prospective adopters. A firm's employees must undertake a learning phase to develop competencies and new processes during technological-induced change (Ahsan, Ozer, \& Alakent, 2010). Cullen, Edwards, Caspter and Gue (2014) added that changing employee mind-sets and behaviours is much harder than changing a process or system. Every innovation has potential users that will either adapt or resist its use (Hutchings \& Quinney, 2015). A significant problem for many business leaders is that they fear employee resistance and do not use resistance as an opportunity to engage and learn (Ali, Zhou, Miller, \& Ieromonachou, 2016). Many potential users will adapt and learn new skills, and many will have their competences destroyed. Ahsan, Ozer and Alakent (2010) argued that knowledge and experience will help employees adapt, but an over-reliance on existing techniques and routines will slow down and erode success. Leaders must pursue knowledge both internally and externally and leverage existing experience to help staff move towards competence-destroying change (Ahsan, Ozer \& Alakent, 2010).

Managing and leading employees in a changing environment is critical to overall business success. Hansen, Randolph, Chen, Robinson, Marin and Lee (2015) argued that business leaders must understand that both influencers and opponents seek to encourage imitators, and managers must use institutional pressures to their advantage in changing those very institutions. Thus, managers are needed to anticipate and manage resistance, draw up a plan of action, and a realistic timeline to allow the firm to remain healthy and competitive 
(Cullen, Edwards, Casper, \& Gue, 2014). Some of the strategies of managing employee resistance to change are discussed hereunder:

\section{Effective Communication}

Communication is known as the transfer and understanding of meaning from one to another. According to Davis (2012) Communication is a critical element in managing change, with companies' turbulent environment and introducing new strategies are more often to perform less effective peers. Kotter and Schlesinger (2008) points out that one of the most common ways today to reduce resistance to change through communication by educating people. Communication of the organization vision helps people see the need for and the logic of a change. A weak communications system in the organization is considered to be one of the obstacles on the way of the implementing the change (Kotter \& Schlesinger, 2008). Every managerial function and activity requires some form of communication, whether it is planning, directing, leading or coordinating (Graetz, 2006). Hayton (2015) suggests that poor human communication can lead to conflicts within the organization as expectations are met and during the change management process poor communication can be a barrier to change. Stewart (2009) points out that employees, customers and managers need to communicate effectively and efficiently so that they can exchange information about goal, expectation and performance. Educating the employees through communication is imperative; it helps the employee's understand the mission and vision of the organization. Paton and McCalman (2011) suggest that leaders should create a learning organization through training that can create effective communication so that they can create readiness to change.

\section{Employee Participation in Decision-Making}

Julia and Veronica (2008), point out that participation is limited collaboration. The principle that involvement will equal greater commitment still justifies this approach to change. However, employees are allowed only limited involvement in certain areas of change, such as how the desired change can be achieved. It is a key role for managers and leaders to create the conditions in which individual initiative and teamwork thrive, rather than identify and prescribe in detail what individuals should do; Kotter and Schlesinger (2008). As per Bernard (2011), managers should no longer identify and implement some ideal universal model; they rather should establish, jointly work with those employees that are most closely affected, the structures and practices necessary to operate effectively under the conditions which prevail at any particular point in time (Price \& Chahal, 2007). Employee participation in decision aids the change management process to work efficiently as the employees are the ones who are affected by the change when the decision are made (Burke \& Ghada, 2014). It also motivates the employees as they become the drivers of change because of their inputs in the decision making (Esther \& Mike, 2015). Kotter and Schlesinger (2008) pointed out that if you want resisters to become more committed to the change, encourage their participation in its design or implementation. This method increases grassroots support for change but can cause problems if people lack the expertise to develop effective plans. Though it has been argued by Senior and Fleming (2004) that participation of employee's in decision making can be very time consuming and most of the time these decisions are reactive rather than proactive decision which need immediate attention. 


\section{Collaboration}

In collaboration, there is widespread involvement of employees in both what to change, and how to deliver the needed changes. Employees are asked to contribute to both the goals set for change and the means of achieving those goals. This may be through participative face-toface meeting, such as workshops or focus groups in which, for example, consultants introduce participants to analytical tools and frameworks that can provide new insight on the participants' business and lead to identification of the critical change issues and an explicit consideration of actions to be taken, and by whom (Kreitner, 1992). According to Julia and Veronica (2008), the principle behind collaboration is that the more employees are involved, the more likely they are to support and be committed to the change that they have helped design, and the more likely they also are to sell those changes to others in the organization. In other words, collaboration can be used to bypass resistance. Furthermore, collaboration can be used not only to determine what to change and how, but also to create an awareness of the need for change by challenging complacency within the organization.

\section{Negotiating and Motivation}

Management can be able to reduce resistance to change by negotiating and motivating the employees during the change management process so as to eliminate the resisters to change (Jansen, 2008). Bernard (2011) emphasis that negotiation during the change management process is important so as to reduce the resistance to change, he also adds that the organization must keep the employees satisfied through motivation so that they are able to retain employees who would be drivers of change in the organization. For instance, management could give a higher wage reward and incentives to the employees so that they are motivated to take the part in the change process.

Negotiation is particularly appropriate when it is clear that the employee is going to lose out as a result of a change and yet his or her power to resist is significant (Jukka, Timo, \& Markku, 2011). Negotiated agreements can be an easy way to avoid major resistance, though, like some other processes; they may become expensive (Kotter \& Schlesinger, 2008). Jukka et al., (2011) suggested that the management can improve the employees satisfaction by improving the position of the employee through promotion so as to motivate the employee during the change process, they also add that not only the improvement of position will bring about the motivation but also the participation of the employee during decision making. Increase in salary can also be used to motivate the employee which makes the employee feel appreciated of the efforts that they had put are being recognized by the organization. Other benefits such as higher bonuses can also be considered by the organization to motivate the employees to go through the change process knowing that they will be regarded at the end of it for the discomfort they will be facing (Burke \& Ghada, 2014).

\section{Effective Direction}

When those leading change make the majority of decisions about what to change and how, and use their authority to direct the achievement of change, this is a management style of direction. This approach effectively separates the thinkers from the doers. The thinkers come up with the change ideas and 'sell' them to the doers, who are then supposed to implement these plans and the ideas. There may still be an attempt to sell the changes to the employees, to encourage them to buy effort in which employees are involved in workshops to debate the implications of change for themselves. However, employees are not invited to contribute to the 
goals or means of change, except in a limited way. Many turnarounds, for example, involve this style of change (Julia \& Veronica 2008).

\section{Effective Reward Management}

Mejia-Morelos, Grima and Trepo (2013) suggested that for leaders and managers to secure the desired results of change, they have to go through compensation and reward philosophy that recognizes employees for their performance and acknowledgement of efforts put in when undergoing the change process. Rewarding change efforts demonstrates the importance of and need for change, along with leaders' understanding that "the things that get rewarded get done." There is a common business saying that "the managers get what they reward" (McKnight, 2005). Organizational employees will resist change when they do not see anything in it for them in terms of rewards. Without 'WIIFM' (What Is In For Me) or a reward, there is no motivation to support the change over the long run. This often means that organizational reward systems must be altered to support the change that management wants to implement. The reward does not have to always be major or costly (Mejia-Morelos, Grima, \& Trepo, 2013).

An effective compensation and reward system takes into account the dynamic nature of the organization's change initiatives while allowing the firm to establish and navigate its ultimate course. Consequently, effective compensation and rewards are fluid, dynamic, and constantly changing (Jorgensen, Owen \& Neus, 2009). Compensation and reward research suggests that an integrated reward system supports each step of the organization's change implementation. The recipients of the change will react positively to rewards for incremental change and strategic changes, celebrations of milestone achievements, and leaders who create win-win situations related to change (McKnight, 2005). Reward programs help organizations achieve specific change goals such as improved creativity, innovative products and services, competitiveness and willing to work harder, collaboration and teamwork within the organization, employee commitment and loyalty, long-term plans, and continual learning and application of new skills are positively adopted related to organizational goal achievement (Jorgensen, Owen \& Neus, 2009).

\section{Employing Coercion}

According to Julia and Veronica (2008), coercion is an extension of direction. Here change is imposed on employees, rather than staff having the idea of change sold to them. It is a way of achieving rapid change, but as with direction, it may lead to greater resistance. Given the lack of effort devoted to explaining the need for change to staff, or to encouraging buy-in for the changes, this approach is unlikely to work unless there is a very real crisis that is felt by most employees within the organization. However, unless the coercion is such that all aspects of behavioural change can be enforced in some way, the result may still be lip-service to the changes rather than actual change (Julia \& Veronica, 2008).

\section{Conclusion}

Organizations are constantly being forced to go through continuous adaption due to factors like progressive globalization, increased competition, change in information technology, and deregulation. Increasingly, managing change is seen as a permanent business function to improve efficiency and keep organizations adaptable to the competitive marketplace. Many organizations strategically use change to improve organizational 
effectiveness. But bringing about successful change in today's competitive environment requires thoughtful planning, effective communication and employee acceptance. Resistance to change is considered to be one of the key factors in failing on the success of changes in business. People resist change because changes are seen as a threat to them, their status and financial rewards. Change management programs must have been the result of the fact that many people resist change. There are many people who are stimulated by change and see it as a challenge and an opportunity. But they are scarce.

\section{Recommendations}

i. It is imperative that managers should be trained to possess the requisite skills and competencies in change management so that they could efficiently handle all forms of resistance from employees.

ii. It is recommended that managers should study the root causes of employee resistance to change so that appropriate corrective measures and strategies would be developed in managing employee resistance.

\section{References}

Abraham, R. (2000). Organizational cynicism: Bases and consequences. Genetic, Social, and General Psychology Monographs, 126(3), 269-292.

Ahsan, M., Ozer, M., \& Alakent, E. (2010). Incumbent's adaption to competence destroying change: Role of prior experience and knowledge sourcing. Journal of Management Issues, 22, 456-475.

Alexander, P. (2007). The impact of organizational culture in managing the change to the use of FOSS at a South African University. Journal of Organizational Change Management, 26(2), 370-422.

Ali, M., Zhou, L., Miller, L., \& Ieromonachou, P. (2016). User resistance in IT: A literature review. International Journal of Information Management, 36(1), 35-43.

Balogun, J. \& Hailey, H. V. (2004). Exploring strategic change, 2nd ed. London: PrenticeHall.

Bernard, B. (2001). No such thing as ... a "one best way" to manage organizational change. Management Decision, 11 - 18.

Bryant, D. (2011). Managers as change agents during a public sector merger. Journal of Organizational Change Management, 6(1), 231-306.

Burke, R., \&Ghada, E.-K. (2014). Human resource management practices in small- and medium-sized enterprises in Egypt. Journal of Transnational Management, 7(10), 211226.

Burke, W. W., Lake, D. G., \& Paine, J. W. (2009). Organization change: A comprehensive reader. San Francisco: Jossey-Bass.

Burnes, B. (2004). Managing cChange: A strategic approach to organizational dynamics.(4th Ed.). Harlow: Prentice Hall.

Chawla, A., \& Kelloway, E.K. (2004). Predicting openness and commitment to change. Leadership \& Organization Development Journal, 56(6), 485-498. 
Coetsee, L. (1999). From resistance to commitment. Public Administration Quarterly, 23, 204 222.

Cullen, K., Edwards, B. D., Casper, Wm. C., \& Gue, K. R. (2014). Employees' adaptability and perceptions of change-related uncertainty: Implications for perceived organizational support, job satisfaction, and performance. Journal of Business and Psychology, 29, 269-280.

Darling, R.J., \& Taylor, E.R. (2005). Feeling bad: antecedents and consequences of negative emotions in ongoing change. Journal of Organizational Behavior, 26(8), 875-897.

Davis, J. P. (2012). Strategy and Leadership: A model for strategy implementation and conflict resolution in the franchise business. London, UK: Oxford Press

De Jager, P. (2001). Resistance to Change: A new view of an old problem. The Futurist, 24-27

Dent, E., \& Goldberg, S. (1999). Challenging resistance to change. Journal of Applied Behavioural Science, 25-41.

Durbin, A. J., \& Ireland, R. D. (1993). Management and Organization (2nd ed.). Cincinnati: South - West Publishing Co.

Eseroghene Franklin, U., \& Balbuena Aguenza, B. (2016). Obstacles, resistance and impact of change in organizations: An examination of the Saudi telecommunication company (STC). International Journal of Academic Research in Business and Social Science, 6(4), 23-37.

Esther, C., \& Mike, G. (2015). Making sense of change management: A complete guide to the models, tools and techniques of organizational change. London: Kogan Page.

Franck E., Roes L., De Schepper S., Timmermans O. (2018). Team Resource Management and Quality of Care. In: Van Bogaert P., Clarke S. (eds) The Organizational Context of Nursing Practice. Springer, Cham.

Fred, L. (2012). Focus for and resistance to organizational change. International Journal of Management and Strategy, 203.

Fugate. M., Prussia G. \& Kinicki A.J. (2012). Managing employee withdrawal during organizational change: The role of threat appraisal. Journal of Management, 38(3) 890914

Giangreco, A., \& Peccei, R. (2005). The nature and antecedents of middle manager resistance to change: evidence from an Italian context. The International Journal of Human Resource Management, 16(10), 1812- 1829.

Goodstein, L. D. \& Burke, W.W. (1991). Creating successful organization change. Organizational Dynamics, 19 (4).

Graetz, F. (2006). Strategic change leadership. Management Decision, 38(8), 550-562.

Greenberg, J. and Baron, R.A. (2002). Behavior in Organizations. New Jersey: Prentice Hall.

Hansen, H., Randolph, A., Chen, S., Robinson, R. E., Marin, A., \& Lee, J. (2015). Institutional judo: How entrepreneurs use institutional forces to create change. Journal of Organizational Change Management, 28, 1076-1093. 
Hayton, J. (2015). Leadership and Management Skills in SMEs: Measuring Associations with Management Practices and Performance. London: Enterprise Research Centre/Warwick Business School.

Hobman, E. V., \& Walker, I. (2015). Stasis and change: social psychological insights into social-ecological resilience. Ecology and Society, 20(1). doi:10.5751/es-07260-200139

Hodgetts R. M., \& Hegar K. W. (2008). Human Relations at Work. 10th Ed. Ohio: Edward Brothers MI.

Hon, A. H. Y., Bloom, M., \& Crant, J. M. (2011). Overcoming resistance to change and enhancing creative performance. Journal of Management, 40(3), 919-941.

Huse, E. (2008). Impact of organizational change on organizational culture: Implications for introducing evidence-based practice. Journal of Evidence-Based Social Work, 5(1/2), 321-359.

Hutchings, M., \& Quinney, A. (2015). The flipped classroom, disruptive pedagogies, enabling technologies and wicked problems: Responding to 'the bomb in the basement'. The Electronic Journal of e-Learning, 13, 105-118.

Jansen, K.J. (2012). A case study in organizational change: Implications for theory. The Learning Organization, 10(1), 18-30.

Johnson G., \& Scholes, K. (2002). Exploring corporate strategy, 6 th Edition. New Jersey: Prentice Hall. USA

Jones, S. L., \& Ven, d. V. A. H. (2016). The changing nature of change resistance. The Journal of Applied Behavioral Science, 52(4), 482-506.

Jorgensen, H.H., Owen, L., \& Neus, A. (2009). Stop improvising change management. Journal of Strategy and Leadership, 37(2), 38-44.

Jukka, K., Timo, S., \& Markku, T. (2011). Efficient change strategies: Matching drivers and tracers in change projects. Business Process Management Journal, 6(4), 80- 92.

Julia, B. \& Veronica, H. H. (2008). Exploring strategic change. New Jersey: Prentice Hall. Kenya. Constitution of Kenya, 2010.

Karaxha, H. (2019). Methods for dealing with resistance to change. Baltic Journal of Real Estate Economics and Construction Management, 7, 290-299.

Korir J, Mukolive E, Loice, K K. (2012). Change Management Effects on Hotel Performance. Journal of Social Science Tomorrow, 1(8) 123 - 131

Kotler, J.P. (2008). Principles of Marketing. New Jersey, N.J: Pearson Prentice Hall.

Kotter, J. P., \& Cohen, D. S. (2002). The Heart of Change. Boston, MA: Harvard Business School.

Kotter, J. P., \& Schlesinger, L. (2008). Choosing strategies for change. Harvard Business Review, 86-130.

Kotter, J.A. (2008). Choosing strategies for change. Harvard Business Review, 57(2), 106-114.

Kreitner, R. (1992). Management (5th ed.). Cincinnati: Houghton Mifflin Co. 
Lawrence, G. (2013). Making strategy work: Leading effective execution and change. Hamilton, NJ: Pearson FT Press.

Leana, C.R., \& Barry, B. (2000). Stability and change as simultaneous experiences in organizational life. Academy of Management Review, 25(4), 753-759.

Lewin, K. (1951). Field Theory in Social Science: Selected Theoretical Papers (ed. Cartwright $D)$. New York: Harper \& Row.

Lines, R. (2004). Influence of participation in strategic change: Resistance, organizational commitment and change goal achievement. Journal of Change Management, 4(3), 193-215.

Lippert, S. K., \& Davis, M. (2006). A conceptual model integrating trust into planned change activities to enhance technology adoption behaviour. Journal of Information Science, 32(5), 434-448.

Lunenburg, F. (2010). Forces for and resistance to organizational change. National Forum of Educational Administration and Supervision Journal, 27(4), 1-10.

Mabin, V., Forgeson, S., \& Green, L. (2001). Harnessing resistance: Using the theory of constraints to assist change management. Journal of European Industrial Training, 25(2-4), 168-191

Mathooko, S. R. (2013). Performance Measurement and Control Systems for Implementing Strategy. Upper Saddle River, NJ: Prentice Hall.

McKnight, R. (2005). HR's Role in Strategy. Right Management Consultants.

Mejia-Morelos, J.H., Grima, F., \& Trepo, G. (2013). Change and stability interaction processes in SMEs: a comparative case study. Journal of Organizational Change Management, 26(2), 370-422.

Moran, J.W. \& Brightman, B.K. (2011). Leading organizational change. Career Development International, 6(2), 111-118.

Morrison, H. (2015). Commitment to organizational change: Extension of a three component model. Journal of Applied Psychology, 6(4), 8-20.

Mutihac, R. (2010). Managing resistance and the use of internal communication in organizations undergoing change. Aarhus School of Business, Department of Language and Business Communication process. In J. M. Jermier, D. Knights, \& W. R. Nord (Eds.), Resistance and power in organizations, 1-24. New York: Routledge

Okenda, R., Thuo, A. \&Kithinji, M. (2017). Effects of change on organizational performance: A case of the Ministry of Environment, Water and Natural Resources. International Academic Journal of Human Resource and Business Administration, 2(3), 501-520.

Oreg, S. (2006). Personality, context, and resistance to organizational change. European Journal of Work and Organizational Psychology, 15(1), 73-101.

Paton, R.A., \& McCalman, J. (2011). Change mManagement: A guide to effective implementation. California: SAGE Publications. 
Piderit, S. K. (2000). Rethinking resistance and recognizing ambivalence: A multidimensional view of attitudes toward an organizational change. Academy of Management Review, 25(4), 783-794.

Price, D., \& Chahal, K. (2007). The impact of change on performance. Journal of Change Management, 2(2), 160-172.

Prokesch, S. (2009). Organizational culture and leadership: A dynamic view. San Francisco: Jossey-Bas.

Raineri, A. B. (2011). Change management practices: Impact on perceive change result. Journal of Business Research, 64,266-272.

Samuel, K. (2013). The effects of change management in an organization: A case study of national university of Rwanda. Wyno Journal of Management and Business Studies, $1(1), 1-18$.

Schermerhorn, J., Hunt, J., \& Osborn, R. (2005). Organizational Behaviour. Manhattan, NY: John Wiley \& Sons, Inc.

Senior, T., \& Fleming, J. (2004). Employee commitment and motivation: A conceptual analysis and integrative model. Journal of Applied Psychology, 89.

Ude, S., \& Diala, I. (2015). Support for creativity and innovation, resistance to change, organizational commitment and motivation. International Journal of Computer \& organization Trends (IJCOT), V5 (4), 1-8.

Wanberg, C. R., \& Banas, J. T. (2000). Predictors and outcomes of openness to changes in a reorganizing workplace. Journal of Applied Psychology, 85(1), 132-142.

Wenhe, Y. (2011). Resistance, the Echo of Change. International Journal of Business and Management, 13 (4), 84-89. 